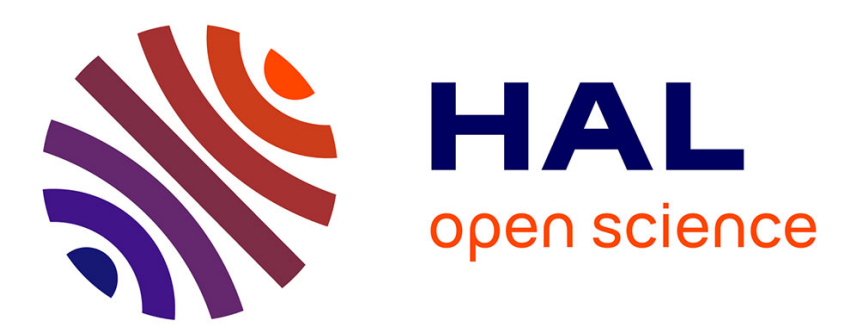

\title{
The strategy of parallel approaches in projects with unforeseeable uncertainty: the Manhattan case in retrospect
}

Sylvain Lenfle

\section{To cite this version:}

Sylvain Lenfle. The strategy of parallel approaches in projects with unforeseeable uncertainty: the Manhattan case in retrospect. International Journal of Project Management, 2011, 29 (4), pp.359-373. hal-00658346

\section{HAL Id: hal-00658346 https://hal.science/hal-00658346}

Submitted on 10 Jan 2012

HAL is a multi-disciplinary open access archive for the deposit and dissemination of scientific research documents, whether they are published or not. The documents may come from teaching and research institutions in France or abroad, or from public or private research centers.
L'archive ouverte pluridisciplinaire HAL, est destinée au dépôt et à la diffusion de documents scientifiques de niveau recherche, publiés ou non, émanant des établissements d'enseignement et de recherche français ou étrangers, des laboratoires publics ou privés. 
THE STRATEGY OF PARALLEL APPROACHES IN PROJECTS WITH UNFORESEEABLE

UNCERTAINTY: THE MANHATTAN CASE IN RETROSPECT.

Sylvain Lenfle

Published in the International Journal of Project Management

Vol. 29, n²4, pp. 359-373, may 2011

\begin{abstract}
This paper discusses the literature on the management of projects with unforeseeable uncertainty. Recent work demonstrates that, when confronted with unforeseeable uncertainties, managers can adopt either a learning, trial-and-error-based strategy, or a parallel approach. In the latter, different solutions are developed in parallel and the best one is chosen when enough information becomes available. Studying the case of the Manhattan Project, which historically exemplifies the power of the parallel approach, has lead us to show that the either/or logic underlying the existing literature on the parallel approach oversimplifies the question. The Manhattan case demonstrates that managers must not necessarily choose between solutions, but can also combine them or add new ones during the project.
\end{abstract}

Keywords: Project Management, Parallel Approach, Combination, Unforeseeable uncertainty, Innovation, Manhattan Project 


\section{Parallel: being everywhere equidistant and not intersecting}

\section{INTRODUCTION}

The strategic role of new product development and innovation makes design performance a central concern of managers [26, 30,67]. Project management therefore appears to be an adequate solution to the integration problems raised by those activities. Yet, in line with work on project classification [60,67], we believe that a distinction should be drawn between the various design situations to which different types of projects will be suited. In a previous paper [46], we noted the gap between the definition of "project" that highlights novelty, and a mainstream literature which proposes an instrumental view of project management. Though criticized in recent years (see International Journal of Project Management, special issue on Rethinking Project Management, 2006, vol. $24, n^{\circ} 8$ ), this "rational” view of project management as the accomplishment of a clearly defined goal in a specified period of time, and in conformity with certain budget and quality requirements, remains dominant in most textbooks and discussions of the topic. But is such a view useful for understanding innovation management? Actually, innovation is first and foremost characterized by divergence and discovery [65], as well as by unforeseeable uncertainties which render the rational approach irrelevant [49, 52].

Contemporary research therefore argues for an alternative model in which project management is seen first and foremost as an experimental learning process [49, 52, 53], and as a way to organize and structure exploration and search $[19,46]$. This emerging view raises important managerial questions, particularly concerning ways to manage the unknown [47, 49]. In a situation in which nobody can anticipate how things will develop, the basic scheme of a project involves a Plan / Do / Check / Act cycle "embedded in a process of a stream of learning events” [49, p. 118]. How to conduct the different experiments therefore becomes a central practical and theoretical issue [50]. Should they be treated sequentially or in parallel?

The purpose of this article is to analyze the problems raised by the management of parallel trials in projects with unforeseeable uncertainties. As we shall see, most of the research on this question deals with the choice between sequential or parallel approaches. While unquestionably 
crucial, such an orientation neglects the other side of the coin, namely the question of deciding how to manage the different trials once a strategy has been chosen.

To deal with this issue we will go back to history. One of the most famous cases of a project relying on the parallel approach is the Manhattan Project which, during the Second World War, led to the development of the atomic bomb. This case is worth studying for at least two reasons. First, the Manhattan Project brought about a major breakthrough in the history of technology. Second, since early on it has been frequently cited to illustrate the power of the parallel approach (e.g. Nelson, 1959). The Manhattan Project thus constitutes an exemplary case, and may offer valuable insights into the management of parallel trials in situations characterized by unforeseeable uncertainties [68].

The present article is organized as follows: We begin by discussing the literature on the parallel approach. Section 2 describes (§3) our methodology. Section 4 presents the history of the Manhattan Project. We thereafter analyze the management of the parallel approach and its implications for project strategy (§5). Section 6 discusses the technical and organizational problems raised by such a strategy. We conclude by pointing out that the management of the parallel approach in projects with unforeseeable uncertainty constitutes an important research topic - one that should lead us to rethink the role of projects in the strategy process.

\section{Literature ReView: Parallel Strategy in Project Management}

The most important problem faced by managers of project with unforeseeable uncertainty is that the entire endeavour is first and foremost characterized by unknown unknowns, i.e. by "the inability to recognize and articulate relevant variables and their functional relationships” [62, p. 1334]. This means that the project team faces a situation where events can occur that are outside its knowledge, and for which it cannot plan or prepare. In contemporary terms, Project Risk Management is no longer efficient since nobody can identify and anticipate the risks [49].

One way of confronting unforeseeable uncertainties consists of trying different approaches in parallel to find out which one works best. In a late-1960s study of R\&D projects, Abernathy and Rosenbloom [18] defined "a parallel strategy as (...) the simultaneous pursuit of two or more distinct approaches to a single task, when successful completion of any one would satisfy the task 
requirements". They distinguished it from the sequential strategy, which is commited "to the best evident approach,” and takes up other possibilities "only if the first proves unsuccessful”. As they explained, the benefits of the parallel approach are straightforward, since "by following more than one approach, the manager avoids the risk inherent in trying to discern a priori which of the several uncertain avenues will prove best. By this means he can obtain information that will permit a better choice among approaches, hedge against the risk of outright failure, and perhaps gain indirect benefits by stimulating competition effort or building a broader technological competence for the organization” (p. B-486). In the remaining of this article, parallel approach will designate a project which explores simultaneously different approaches, solutions or trials (we shall use these three words interchangeably). The term strategy will refer here to project strategy [21], i.e. to how the different solutions are managed as the project unfolds.

We can identify chronologically three independent streams of research dealing with the parallel approach: early literature on project management, research on modularity, and recent work on project management based on search theory. We present them successively.

The roots of the parallel approach can be traced to the work of the RAND Corporation in the 1950s. In their analysis of the R\&D process within the US Air Force, RAND economists criticized its excessively centralized character [39]. Given the inherent uncertainty of the R\&D process (and uncertainty was very great during the 1950s due to the development of new weapons such as Thermonuclear Intercontinental Ballistic Missile), they plead for a policy "in which diversity [would be] the optimal principle of choice" [20] since, in such cases, "avoidance of duplication [would] not necessarily [be] a virtue” [22]. Their criticism targeted systems analysis, which tried to specify the entire system before the onset of development. The result was pioneering work in the economics of parallel R\&D [43, 56]. In particular Nelson [56], following Klein and Meckling’s landmark contribution [43], argued in 1959 that given the relatively low cost of preliminary studies, "it may be economical not to choose one design or contractor for an $R \& D$ job on the basis of first estimates which experience has shown to be notoriously unreliable, but rather to initiate parallel-development efforts, cutting down the list of competing projects as estimates improves" (p. 3-4, emphasis in the 
original). His article orientated most later research on parallel strategy. In order to illustrate the strength of such an approach, Nelson relied on the Atom Bomb project that we are going to study.

First, Nelson emphasized that the parallel approach does not imply duplication, since the designs pursued are different. Second, in his framework, as in most work on this topic, the project under consideration concerned a process that envisaged several solutions from the outset, and established that one would be selected for development only after "significantly improved estimates" had been made available [56]. Third, finding out how many trials should be run in parallel became the key question. RAND research concluded that the marginal utility of additional trials would decrease rapidly beyond three or four parallel trials [38]. Finally, Nelson [56] insisted that the parallel approach would be most suitable in situations where "there is not sufficient scientific knowledge for a final choice to be made with any great confidence and the pressure of time is too great to permit alternatives to be tried one after another" (p. 33). Such emphasis on the role of available time is crucial since "if time is not of major importance (...) more background research should be undertaken before a development effort is undertaken at all" (footnote, p. 35).

The parallel approach disappeared in the late 1960's from the literature on project management [48]. Since then, research on product architecture has nonetheless reintroduced in the management literature the idea that such an approach could be a powerful way to deal with uncertainty [23, 45, 58]. Sanchez and Mahoney [58] demonstrate that a modular product architecture enables several teams of designers to work in parallel on the same module, and may therefore accelerate a firm's learning about markets by enabling it "to leverage many different variations of a product more quickly and at reduced cost” [58, p. 72]. Baldwin and Clark [23] further analyze the option value of such an approach and the tremendous impact it has had in the computer industry.

Contemporary research on the management of projects with unforeseeable uncertainty is rediscovering the power of the parallel approach but, interestingly, without any reference to RAND research. Christoph Loch and his colleagues refer to this approach as selectionism [49, 57, 62]. They develop a framework to help project managers choose among different strategies according to the specificity of their situation. The criteria used are 1) the complexity of the project, and 2) the relative cost of learning and delay as compared to parallel trials. Loch rejoins Nelson’s conclusions in 
demonstrating that the selectionist (i.e. parallel) approach is the most appropriate when the project offers great complexity, and when the costs of delay and learning are high in comparison with those of parallel trials. His work thus considerably improves our knowledge concerning the information that is needed to choose between sequential and parallel approaches. Moreover, Loch proposes a distinction between a "pure" parallel approach (called Darwinian), in which different trials are launched on the market, and an exploratory strategy closer to Nelson's framework, in which the best solution is selected before development.

Nevertheless, like earlier work, Loch’s frame of reference remains mostly a static one, and is ultimately aimed at determining ways of choosing between sequential and parallel approaches. At the same time, Loch and his colleagues insist on the need, in the parallel approach,

- to organize communication among the different teams that pursue the parallel alternatives;

- to choose an approach leading to robust results, i.e. results "that emerge from different trials and hold under a variety of conditions" [49, p. 136]; since costs are lower at the beginning of a project, the sooner options are selected, the better;

- to draw benefits from non-selected trials by exploiting the knowledge they generate.

The goal of such work has been to ensure that resources are committed to the chosen solutions, i.e. to the ones that emerge as the best in the context of a project and its environment. Loch and his colleagues, however, have not provided a satisfactory illustration of how such management process evolves. Indeed, existing theories of the parallel approach focus on situations where solutions are, at least implicitly, given at the beginning of the project. Selecting the "best" trials is therefore their central concern. In short, a process theory [55] of parallel trials management is still lacking, and the problems raised by the parallel approach remain to be further analyzed. The research question then shifts from determining how to choose between trials, toward how to manage the parallel approach during a project. In this paper we propose to examine such a process, and raise the following questions: Are the parallel trials independent? Are they given at the beginning? Can they be combined? What are the organizational and managerial consequences of the parallel approach? In other words, what could the strategy of a project relying on the parallel approach be? 


\section{METHODOLOGY}

What we are looking for is a process theory of parallel approach management [55]. The natural methodology here is that of the longitudinal single case study [68]. Finding appropriate cases, however, proves difficult. Most of the time, R\&D projects with a high degree of innovativeness, and thus of uncertainty, are considered confidential, and are therefore closed to both quantitative and qualitative outside assessment. One way to overcome this problem is to go back to history. Surprisingly, such an approach, widely used by historians, sociologists of technology [41] or economists [33], is rarely used by scholars working on project management or innovation (a notable exception is Hargadon [35, 36]). History, however, constitutes a powerful way to test the relevance of existing theory or to generate insights on contemporary questions [42, 61].

The Manhattan Project is for two reasons an obvious candidate. First, it constitutes the seminal reference in the early literature on parallel approach in R\&D projects. Revisiting the case can thus help discuss the contributions and limitations of the early scholarship. Second, the making of the atomic bomb unquestionably represents a major breakthrough in the history of technology. It exemplifies the power of "Big Science," the large-scale mobilization of human, financial, and industrial resources to overcome major scientific and technical problems. As noted by Hoddeson et al. [6], the managerial practices developed at the Los Alamos Laboratory were widely taken up in the American scientific and industrial community after World War II. Studying how the breakthrough happened may provide insights into innovation management.

Fortunately, the Manhattan Project has been extensively studied, mainly by historians, and its relevance no longer needs to be proved. We may therefore draw on a large amount of historical material that has so far not been used to study innovation management. Our objective is not to provide a comprehensive account of the Manhattan Project, but to focus on a specific set of events that, we believe, reveal the problems raised by the management of parallel approach in projects with unforeseeable uncertainty (we therefore do what Langley [4] refers to as bracketing events for theoretical purposes). We will nonetheless include details that are critical for our argument that the management of parallel trials is more complex than an either/or choice. We relied both on the “official” history of the project [3, 4, 5, 7, 14], and on more recent work (especially Rhodes, [12]). We 
also drew on research focused on a person $[1,11,16]$, on a specific part of the Project $[6,15]$, or on a specific question $[10,13]$. Given the information available, we consider that the point of "theoretical saturation,” which Glaser and Strauss [3] proposed as criterion to stop collecting data, has been attained. Our analysis may therefore lack empirical originality, but will hopefully triangulate the data in original ways.

\section{History Of The Manhattan Project}

In this section we will summarize the main steps of the project by studying, first, the technical problems it had to face, and second, how these problems were overcome both at a general and at micro level. Our focus remains the parallel approach. Thus many technical problems encountered by the project are not described here (see [47] for a more complete description).

\section{A Scientific and Technical Everest}

To understand the difficulties the Manhattan Project had to face we first have to delve a bit into nuclear physics and, second, identify the main design problems raised by the making of an atomic bomb.

\section{Nuclear physics background}

The Manhattan Project did not start from scratch. As explained by Princeton physicist Henry DeWolf Smyth in his Official Report on the Development of the Atomic Bomb under the Auspices of the United States Government, which was released just after Hiroshima and Nagasaki, “The principal facts about fission had been discovered and revealed to the scientific world. A chain reaction had not been obtained but its possibility - at least in principle - was clear and several paths that might lead to it had been identified. [14, p. 364]. "All such information," he added, “was generally available; but it was very incomplete. There were many gaps and many inaccuracies. The techniques were difficult and the quantities of materials available were often submicroscopic. Although the fundamental principles were clear, the theory was full of unverified assumptions, and calculations were hard to make. Predictions make in 1940 by different physicist of equally high ability were often at variance. The subject was in all too many respects an art, rather than a science (ibid, p. 365). 
Scientifically the problem was the following (figure 1). As demonstrated by Lise Meitner and Otto Frisch in 1938, when a neutron hits a uranium atom, the latter splits into two parts, releasing energy and additional neutrons, which in turn split and bring about a chain reaction. Some of the major scientific challenges consisted of establishing the critical mass of fissionable material needed to start and sustain a chain reaction, and of determining the number of neutrons released at each step (the reproduction factor k), knowing that they can be lost or absorbed by other materials.

\section{INSERT FIGURE 1 ABOUT HERE}

Meitner and Frisch's discovery was a true revolution since "the newly discovered reaction was ferociously exothermic, output exceeding input by at least five orders of magnitude. Here was a new source of energy like nothing seen before in all the long history of the world" (R. Rhodes, in [13], p. xiii).

\section{From theory to practice}

The first self-sustaining nuclear chain reaction was obtained by Enrico Fermi and his team at the University of Chicago in December 1942. Thereafter, the Manhattan Project faced two major problems: the production of fissionable materials, and the design of the bomb itself. These problems were aggravated by time pressure. Indeed, the US government feared that Nazi Germany would build the bomb first; therefore, by November 1942 already, it had been decided to skip the pilot phase and move directly from research to full-scale production.

\section{The production of fissionable materials}

Two materials capable of sustaining a chain reaction were identified at the beginning of the Project. One, uranium 235, is a component of natural uranium (U238), but represents only $0,72 \%$ of its mass. The other, plutonium (Pu239), is a by-product of nuclear fission discovered by Glenn T. 
Seaborg in 1941. In both cases, the production of fissionable materials raised huge scientific and technical problems:

- Separating U235 from U238 involves extremely complex processes, based on the slight differences in the atomic mass of the two isotopes (less than 1\%). Seven different separation methods were identified in 1941; as we shall see, three of them would finally be used [14].

- Plutonium production involves the design and construction of nuclear reactors and the associated chemical separation plants. Twelve separation processes were studied at the University of Chicago "Met Lab” at the beginning of plant construction.

These were breakthrough innovations. The processes either did not exist before the project (plutonium production) or had never been used with radioactive materials (chemical separation). They entailed extremely tight requirements, and involved radioactive (and therefore very dangerous) materials. Above all, the available knowledge about the production, metallurgy and chemistry of plutonium and uranium separation was far from complete. Thus, commenting on the 1943 Met Lab plutonium research program, Smyth observed that "Many of the topics listed are not specific research problems such as might be solved by a small team of scientists working for a few months but are whole fields of investigation that might be studied with profit for years. [So] it was necessary to pick the specific problems that were likely to give the most immediately useful results but at the same time it was desirable to try to uncover general principles" [14].

\section{$\underline{\text { Alternative bomb designs }}$}

The team faced a similar situation regarding the design of an atomic bomb. In a seminar organized at Berkeley by Oppenheimer in July 1942, scientists discussed bomb designs (figure 2 on the right, from [13]). Several fission bomb assembly possibilities were envisioned: the gun method (at top), the implosion method (center), the autocatalytic method, and others. In the end, only the "gun" method and a more complicated variation of the "implosion" design would be used; as we shall see, the path toward them was not simple. Furthermore, the Berkeley discussion was theoretical, since no prototypes had so far been built, nor experiments undertaken. It remained to be shown, for example, 
whether a "gun” design worked for uranium and plutonium, or whether an "implosion” device was at all feasible.

\section{INSERT FIGURE 2 ABOUT HERE}

\section{Managerial implications}

Such a situation had fundamental managerial implications. The most important one was that the entire project was first and foremost characterized by unforeseeable uncertainties. As Groves [3, p. 19]wrote, "the whole endeavour was founded on possibilities rather than probabilities. Of theory there was a great deal, of proven knowledge, not much”. He quickly realized the implications of such a situation. First, he recognized the impossibility of establishing a reliable plan of the project. A "tentative construction program” had emerged out of the Berkeley seminar. But "[i]t soon became apparent that these target dates were wholly unrealistic, for basic research had not yet progressed to the point where work on even the most general design criteria could be started" (ibid, p. 15).

In short, the required knowledge was largely non-existent at the outset of the project. At the end of a meeting with scientists at the University of Chicago on October 5, 1942, soon after his nomination as Project director, Groves "asked the question that is always of uppermost in the mind of an engineer: with respect to the amount of fissionable material needed for each bomb, how accurate did they think their estimate was? I expected a reply of "within twenty-five or fifty percent," and would not have been surprised at an even greater percentage, but I was horrified when they quite blandly replied that they thought it was correct within a factor of ten. This meant, for example, that if they estimated that we would need on hundred pounds of plutonium for a bomb, the correct amount could be anywhere from ten to one thousand pounds. Most important of all, it completely destroyed any thought of reasonable planning for the production plants of fissionable materials. My position could well be compared with that of a caterer who is told he must be prepared to serve anywhere between ten and a thousand guests. But after extensive discussion of this point, I concluded that it simply was not possible then to arrive at a more precise answer" (ibid, p. 40). He thus concluded: "While I had known that we were proceeding in the dark, this conversation brought it home to me with the impact 
of a pile driver. There was simply no ready solution to the problem we faced, except to hope that the factor of error would prove to be not quite so fantastic" (ibid.).

\section{Managing unforeseeable uncertainties: parallel approach and concurrent engineering}

Considering unforeseeable uncertainties, Groves and the Steering Committee (most notably V. Bush and J.B. Conant) decided to explore and implement simultaneously the different solutions, both for the production of fissionable materials and for bomb design. First, given the utmost importance of time, the various possibilities would be pursued in parallel. As Conant told Bush early on, «All fives methods ${ }^{1}$ [of uranium separation] will be entering very expensive pilot plant development during the next six months. ... [but] while all five methods now appear to be equally promising, clearly the time to production... by the five routes will certainly not be the same but might vary by six months or a year because of unforeseen delays. Therefore, if one discards one or two three of these methods now, one may be betting on the slower horse unconsciously» (Conant to Bush, May 14, 1942, in [56]).

Second, both fundamental research, and the design and building of the plant would be carried out at the same time. Groves had already used concurrent engineering, but it was the first time such a strategy was extended to fundamental research. As he explained: "I had decided almost at the very beginning that we have to abandon completely all normal orderly procedures in the development of the production plants. We would go ahead with their design and construction as fast as possible, even though we would have to base our work on the most meager laboratory data » [3, p. 72]. Thayer [15, p. 42] has shown that DuPont pushed this strategy to "its ultimate extreme" in the management of the Hanford Project, which led to plutonium production. Indeed, following Groves’s decision, DuPont engineers chose "to design and build the plant and to develop its unprecedented components and processes in parallel with each other, with the development of supporting science, and with the design and operation of the semiworks [at Oak Ridge]" (ibid. p. 41). Shortening project duration was clearly the goal: «Always we assumed success long before there was any real basis for the assumption; in no other way could we telescope the time required for the over-all project. We could never afford the luxury of awaiting the proof of one step before proceeding with the next » [3, p. 253].

\footnotetext{
${ }^{1}$ They will rapidly be reduced to 2 .
} 
We have used published sources to clarify the meaning of this strategy, emphasizing the development of the Project and its different phases. Figure 3 summarizes the organization of the Project, and Figure 4 its progression. "SoP” designates "start of production (black points in Figure 4). (A timeline is available in [8]; we have completed it with [2, 5, 14, 12]).

\section{INSERT FIGURE 3 AND 4 ABOUT HERE}

The simultaneity of the different tasks is striking:

- Uranium separation, plutonium production and bomb design proceeded simultaneously;

- for uranium separation two different methods were used in parallel (electromagnetic separation and gaseous diffusion), and a third one was added in September 1944 (thermal diffusion);

- the Los Alamos laboratory explored several different methods at the same time, with the "gun" as the first priority, the "implosion" design as a back-up, and the "fusion" design as a long-term research topic.

The rationale behind the parallel approach was straightforward: given technical and scientific unforeseeable uncertainties, the simultaneous pursuit of different solutions increased the likelihood of success.

\section{Unfolding of the project}

This overview of the project, while necessary to appreciate the global managerial strategy, does not yet allow us to grasp the relevant processes at a micro level. To this end, we shall examine the unfolding of the project, focusing on the events that have led us to question usual views of the parallel approach. By the spring of 1944, none of the methods for producing enriched uranium had achieved sufficient enrichment rates; moreover, the "gun” design for the bomb appeared to be unsuitable for plutonium, which exhibited a much higher "spontaneous fission" rate than anticipated. The project had maneuvered itself into a dead end: it now had a fissionable material (plutonium) without a bomb design, and a bomb design (the "gun”) without a workable fissionable material (uranium 235). 


\section{Production of fissionable materials : the Thermal Diffusion process.}

In the spring of 1944, recurrent problems with gaseous diffusion and electromagnetic separation gave rise to a crisis. By that time, none of the initial delivery schedules had been respected, and the Los Alamos laboratory was desperately waiting for samples of both uranium and plutonium to test its bomb designs.

Aware of the research Philip Abelson was conducting independently for the Navy on the thermal diffusion separation process, Robert Oppenheimer, director of the Los Alamos Laboratory, suggested to Groves in June 1944 that "it might be well to consider using the thermal diffusion process a first step aimed only at a slight enrichment, and employing its product as a feed material for our other plants” [3, p. 120]. The leaders of the Manhattan project thus realized that the different processes could be combined rather than treated as competing solutions. On this basis, Groves acted very quickly. He appointed a committee to survey Abelson's work and contracted with the engineering firm H. K. Ferguson to build a thermal diffusion plant relying on the gaseous diffusion (code-named K25) power plant for electricity supply. They had 90 days to build "twenty-one duplicates” of the Navy experimental plant [5, p. 296]. Production of the thermal diffusion plant (code-named S50) started in early 1945.

Production process at Oak Ridge was completely reorganized as a consequence of such decisions. Following Oppenheimer's suggestion, and knowing that "they had to include several alternatives since the precise operating characteristic of K25 were not yet known," the production committee began to look for the best way to combine the different processes [5, p. 301]. As soon as S50 began to produce slightly enriched uranium, they used it to feed the electromagnetic separation plant (code-named Y12). They did the same with K25 when its production started in January 1945. In February the committee foresaw that the best combination would be from S50 to K25 to Y12 - as was confirmed in April 1945, when K25 demonstrated its capacity to produce the desired amount of enriched uranium. 


\section{The paths to the A Bomb}

\section{Alternative Bomb design at Los Alamos}

In March 1943, in parallel with work on the production of fissionable materials, building of the Los Alamos Laboratory began on a mesa in San Jose desert, New Mexico. Los Alamos was the central node of the Manhattan Project network, and its goal was "to produce a practical military weapon in the form of a bomb in which energy is released by fast neutron chain reaction in one or more of the materials known to show nuclear fission” [13, p. 3].

Such a goal may seem straightforward, but, as was the case for the production of fissionable materials, several bomb designs were possible. Since the beginning, three of them were under study:

1. The Gun design. This solution built on years of experience. Its principle is apparently simple: a piece of fissionable material is thrown against another piece by means of traditional explosives, thus starting the chain reaction (Figure 5). This design would be used in the “Little Boy” bomb dropped on Hiroshima on August 6, 1945.

\section{INSERT FIGURE 5 ABOUT HERE}

2. The Implosion design constituted a breakthrough innovation in weapon design. In this case, conventional explosives are placed around a plutonium core. When they detonate, they are blown inward and the core collapses, thus leading to an explosive chain reaction (Figure 6). This design would be used in the “Fat man” bomb dropped on Nagasaki on August 9, 1945.

\section{INSERT FIGURE 6 ABOUT HERE}

3. The "Super", suggested by Edward Teller and Enrico Fermi, was another radical innovation. It did not rely on fission, but on nuclear fusion. In this design, a fission bomb helps start a fusion reaction in deuterium or tritium, which in turn produces a much more powerful 
explosion than fission bombs. The theoretical foundations of such a weapon were less solid than those of fission designs.

These alternative paths toward an atomic bomb were granted different priority ranks. Given the state of knowledge on weapons and its supposed robustness, pursuit of the "gun” design was top priority. Even if its use with fissionable materials raised important scientific and engineering questions (e.g., on interior ballistics, the shape of the uranium and plutonium parts, the explosives to be used, or detonation), it was believed it could work with both uranium and plutonium. Since plutonium was less well known than uranium, most of the efforts at Los Alamos focused on the plutonium gun. Indeed, a success with plutonium would directly lead to a uranium gun with minor modifications.

Oppenheimer and Groves, however, decided at the outset that they could not rely on a single approach to bomb design. Uncertainties, particularly those surrounding plutonium, were too important. So, in parallel with the "gun” work, Oppenheimer assigned a small group of scientist and engineers to work on the implosion design as a second priority. This was a backup for the plutonium gun; however, as they soon discovered, implosion could also be a much more efficient assembly method than the crude "gun” design. A third group, smaller and with considerably less resources, was assigned to work on the "Super". From the beginning, it was clear to Oppenheimer and his colleagues that the third design was too radical an innovation to be ready during the war. Its potential was nonetheless so high that theoretical work on it was conducted at Los Alamos during the entire project (in part due to E. Teller’s obsession with it).

We thus find at Los Alamos the same managerial philosophy of the entire Manhattan Project: given unforeseeable uncertainties, different solutions are explored in parallel. And this was a good idea since the unforeseeable uncertainties would soon arrive.

\section{The spontaneous fission crisis (July 1944)}

Indeed one important problem in the plutonium gun design was the instability of the new material. In particular, plutonium exhibited a much higher "spontaneous fission” rate than uranium. The two parts of the gun had to strike each other at very high speed. Otherwise the chain reaction 
would start before the two parts collided (and thereby reached the critical mass), and the bomb would “fizzle”. i.e. pre-detonate but not explode.

Although the problem was identified early on, scientists did not master spontaneous fission because plutonium was a completely new material. Measuring and analyzing the phenomenon was therefore an important part of work at Los Alamos. This was particularly challenging since methods and tools had to be developed at a time when plutonium was available only in submicroscopic quantities. The challenge turned to a crisis in April 1944, when Los Alamos received the first reactorproduced samples of plutonium from the X10 air-cooled prototype Pile at Oak Ridge. The material exhibited a spontaneous fission rate five times higher than the already available sample, which had been produced by another process at the Berkeley Cyclotron. Research continued until July, but the results remained desperately the same. The conclusion was clear to Groves, Oppenheimer and their colleagues: the plutonium gun would never work. The entire plutonium path to the bomb (and the millions of dollars already spend) would be lost - and that, at a time when the separation of U235 encountered huge technical difficulties.

To overcome the crisis, Oppenheimer completely reorganized the laboratory. In July 1944, even if engineering questions remained open, the design of the gun was well advanced and under control, at least for uranium [6, p. 411]. Furthermore, the research and experiments on implosion had led to important findings (particularly, John Von Neumann's suggestions during the fall of 1943). In two weeks, Oppenheimer redeployed the resources of Los Alamos so that the entire laboratory would focus on saving the plutonium path [4, chap. 9; 6, chap. 14]. The goal of the new structure was to enhance coordination among the various part of the program. Several committees were put in place to coordinate the work on implosion.

The technical and scientific challenges were colossal. Even if the research and experiments had produced crucial insights, some were questioning the possibility of an implosion design. Indeed “implosion moved the Los Alamos scientists onto new terrain. In part, the move was into areas of physics with which they were less familiar: implosion is a problem in hydrodynamics rather than just in nuclear physics” [9, p. 56]. Symmetry posed the hardest problem: to ensure the onset of a chain reaction, the inward collapse of the plutonium core had to be absolutely symmetric. This had never 
been done before. Since the implosion design would be a breakthrough innovation, the required knowledge was almost non-existent. Los Alamos had to explore simultaneously the hydrodynamics of implosion, the design of the explosive’s "lens” around the core and the initiator that would release the neutrons needed to start the chain reaction (see figure 7), as well as the electronics to coordinate the detonators around the bomb - while keeping in mind that its goal was to design a working weapon. For each question the scientist and engineers of the lab used multiple and overlapping approaches to enrich their understanding of the phenomena at work, increase the likelihood of success, and save time [see 6, for a detailed description].

The herculean scientific and engineering efforts finally led to a radical innovation in weapon design: the implosion bomb. The design was frozen very late, probably on February 28, 1945. Oppenheimer then created the "cowpuncher committee" to oversee the final phase [6, chap. 15 and 16]. Yet the remaining uncertainties around the new device were so great that Groves, finally but reluctantly, and despite the considerable cost it would entail, approved Oppenheimer's request to test the bomb. The Trinity test marked the dawn of the nuclear age. On July 16, 1945, the Manhattan Project tested, in a remote area of the New Mexico desert, the implosion bomb. The test was a success. The "gadget”, as it was nicknamed, exploded with an estimated power of 20,000 tons of TNT and the bombing of Hiroshima and Nagasaki followed three weeks later.

\section{ANALYSIS: THE STRATEGY OF PARALLEL APPROACHES}

The unfolding of the Manhattan Project demonstrates the relevance of the parallel approach in projects with unforeseeable uncertainty. Given unknown unknowns and time constraints, a parallel approach greatly improves the likelihood of success. In the making of the atomic bomb all the solutions, both for the production of fissionable materials and for bomb design, were highly uncertain. It would have therefore been unreasonable to rely on only one of them. Early on, the Manhattan Project leaders knew that if one discarded from the beginning some of the available methods, "one may be betting on the slower horse unconsciously" (Conant to Bush, April 14, 1942, quoted in [56]). Groves translated this strategy directly when he observed, in October 1942, that "If there were a choice between two methods, one of which was good and the other promising, build both. Time was 
more important than money, and it took times to build plants" [5, p. 181]. As explained by Hoddeson et al. [6, p. 406], "the most notable and costly example of multiple approaches was the Pu239 program, created as a backup for U235 production. The decision to create the plutonium program was justified by the complementary uncertainties of producing the two fissionable isotopes - U235 although relatively well known, was difficult to separate chemically from U238, and Pu239, although easy to separate chemically from U238, was almost completely unknown. To save time, the research and production of uranium and plutonium proceed simultaneously". Finally, the decision to explore all the way two completely different bomb designs (gun and implosion) accounts for the success of the project. It should be kept in mind that urgency was the ultimate motivation of the parallel approach. Had there been more time, the Project managers would have probably invested in fundamental research before entering development... and, in all likelihood, the bomb would have not been available before years. This explains why the Manhattan case is the seminal example of the early literature on parallel trials in R\&D projects [e.g. 56].

This literature, however, seems to have missed some interesting characteristics of the case. Indeed, the Manhattan Project highlights hitherto unnoticed strategic moves, namely the possibility of combining different trials and adding new ones during the project. This constitutes a first step in the construction of a process theory of the parallel approaches strategy. In order to make our suggestion clear, we must distinguish three sequences in the Manhattan Project:

- From its inception in the summer of 1942 until mid-1944, the Project is characterized by a pure parallel approach. The different paths were considered like competing horses in a race (a "nuclear steeplechase" in [7]):

- Plutonium was a backup for uranium 235;

- for uranium separation, the electromagnetic process, the first and most promising, competed with gaseous diffusion;

- the implosion design was considered a backup for the much more reliable gun design.

As we have seen, such strategy of competition between trials led to a dead end and gave rise to a major crisis in the summer of 1944 . None of the uranium separation methods reached the 
expected results, and the gun design proved unreliable for plutonium. The Project had produced a bomb design without fissionable materials on the uranium side, and a fissionable material without a bomb design on the plutonium side.

- This crisis opened the way for the second sequence of the Manhattan project, which ended in February 1945 with the design freeze of the implosion bomb and the production committee's conclusion at Oak Ridge that the best process to enrich uranium would be from S50 to K25 to Y12. The main feature of this sequence was the abandonment of the pure parallel approach and the reorganization of the trials portfolio. Indeed, to overcome the crisis, the Manhattan Project leaders, most notably Groves and Oppenheimer, took three major decisions:

1. they decided to add a new separation methods, thermal diffusion, which was considered less promising and had therefore been discarded at the beginning of the project;

2. they realized that the combination of the separation methods for U235 was a better strategy than pure competition; thermal and gaseous diffusion were thus used to feed electromagnetic separation;

3. they redeployed Los Alamos resources from the gun, which had by then become merely an engineering problem, to the implosion design, which required fundamental research as well as engineering.

- The last sequence, from February to August 1945, saw increasing pressure to finalize the designs, organize the tests, and build the base on the Pacific island of Tinian from which the American atomic bomb attacks on Japan would be launched. In this development phase, the Los Alamos laboratory became increasingly structured (weaponized is the term used by Thorpe and Shapin [16]), moving quickly from research to development and production in late 1944 and throughout 1945 [see 5, p. 313-315; 6, chap 14 to 16]. It is remarkable, however, that long-term research in atomic physics and bomb designs was continued throughout this period.

The second step is the most interesting for our topic, since it extends existing literature on the parallel approach. Various authors, from Nelson in 1959 to Loch et al. in recent years, have thought of the parallel approach as an "either/or" choice between solutions that are given at the beginning of the 
project. The benefits of the strategy are described as laying in the flexibility offered by the possibility to delay choices until enough information is available, and, to a lesser extent, in the competition between different teams. The problem for managers is thus supposed to reside in the choice between competing solutions, and the main question is whether the choice takes place before development or after market introduction [49]. Of course, scholars are aware that, when a trial is stopped, managers seek to leverage the benefits of non-selected outcomes by exploiting the knowledge they created and the newly available resources. But the second sequence of the Manhattan Project reveals that the array of choices is larger than an either/or decision, and that the parallel approach may not be strictly “parallel”.

Indeed, the summer of 1944 crisis brought to light an infringement of the parallel logic, and the existence of three additional choices in the strategic management of "parallel” approaches.

First, managers could simply pursue the different solutions to completion, but redeploy the resources among them according to strategic priority or level of advancement. This is what happened when Oppenheimer switched most Los Alamos resources from the gun, which had reached sufficient maturity, to the implosion design. Such strategy allows managers to adapt the intensity of the efforts under way to newly available knowledge, and to face unforeseeable uncertainties.

Secondly - and this is the greatest transgression of parallelism - managers can combine the different trials in order to exploit their complementarities, rather than see them as competing solutions. For instance, the decision to "consider thermal diffusion as a portion of the process as a whole" and to use it (and later gaseous diffusion) as a way to feed the Y12 plant very probably saved the uranium path to the bomb. It could thus be very profitable to consider the various solutions as different sides of the same problem ${ }^{2}$. Thinking of them as complementary could lead to solutions that are better than those that would be reached by the pure parallel approach.

\footnotetext{
${ }^{2}$ This has been identified by D. L. Marples in his classic "The Decisions of Engineering Design” [54]. As he explained, the parallel approach "has other advantages. No one will deny that a problem cannot be fully formulated until it is well on its way to solution. The real difficulty, the nub of a problem lies somewhere amongst the subproblems. (...) The nature of the problem can only be found by examining it through proposed solutions and it seems likely that its examination through one, and only one, proposal gives a very biased view. It seems probable that at least two radically different solutions needs to be attempted in order to get, through comparison of subproblems, a clear picture of the 'real nature' of the problem" (p. 64).
} 
Finally, the second sequence of the Manhattan Project shows that it is also possible to add new trials that have not been selected or even envisioned. In a situation of exploration, it cannot be assumed that every possibility will be identified early on. The essence of unforeseeable uncertainties is precisely to be unforeseeable. Thus, changes in the state of technology, in customers's needs, in competition during the project could make the original options obsolete. Managers are therefore obliged to keep in mind that they are engaged in a search process, and that the initial plan may not be the good one. The late addition of the thermal diffusion method, which had been discarded at the beginning of the project, illustrates this possibility.

\section{INSERT FIGURE 7 ABOUT HERE}

Thus, in the evolution of the Manhattan Project, the original purely parallel approach depicted in Figure 4 mutated radically during the summer of 1944 into a combine/switch/add strategy (Figure 7). Such a development demonstrates that the managerial interest of the parallel approach lies not only in the ability to pick ex post facto the best solution, but also in the ability it gives managers to redeploy resources, combine trials, or add new ones according to changing needs. What is at stake here is the strategic management of a portfolio of trials which constitutes real options [51, 59]. The challenge faced by the project team is to continuously reassess the status of the different trials in order to discover one or several satisfactory solutions. The Manhattan case nevertheless demonstrates that the array of choices is wider than what is suggested in the existing literature on real options. Indeed, to the five classical sources of flexibility (defer, abandon, contract/expand or switch [59]), and to the “improvement” option identified by Huchzermeier and Loch [40], we can now add a hitherto unidentified "combination" option. Furthermore, as we have shown, the portfolio is in continuous evolution since new trials can be added along the way. The strategy of parallel approaches must thus be considered as a dynamic search process within an unknown design space. This has considerable technical and organizational implications. 


\section{DISCUSSION: TECHNICAL AND ORGANIZATIONAL IMPLICATIONS}

Some important questions related to the parallel approaches strategy remain open; they , concern in particular its technical and organizational implications.

The Manhattan case may be illuminating with respect to the technical point of view of the combination option. Indeed, the different processes to enrich uranium were combined... because this was technically feasible. The conditions for doing so were ideal: each process produced the same output, i.e. U235, with different levels of enrichment. One could therefore mix and match them according to need: thermal and gaseous diffusion were used to feed electromagnetic separation, and, later, became steps in the transfer of materials from S50 to K25 to Y12. In contemporary terms, we could say that the interfaces between the different processes were perfectly specified and reduced to a minimum. Except for enriched materials, there was no interaction between the processes. They could be combined without modifying production.

This raises the question of the architecture of the product / processes under development and its managerial consequences. The matter has given birth to an important body of research which demonstrates that the more modular the product, the easier it is to mix and match components according to the situation $[23,37,45,58,64]$. Thus, if we assume that a given project $\mathrm{P}$ has adopted a parallel approach for sub-system $\mathrm{X}$ for which three solutions $\mathrm{X}_{1}, \mathrm{X}_{2}$ and $\mathrm{X}_{3}$ are developed simultaneously, the possibility of combining the three solutions probably depends on the architecture of $\mathrm{X}_{1}, \mathrm{X}_{2}$ and $\mathrm{X}_{3}$. If it is integral, then the only option is to choose the best one, since a change in one component leads to a complete redesign of the sub-system, or to pursuing all options to completion. In the Manhattan Project, the latter was the case with the uranium and plutonium paths. Nevertheless, if the system is even partially modular, with design rules specifying interfaces between at least some of the components, then some type of combination is possible. This is what happened with uranium separation: three processes initially conceived of as competing solutions ended up combined into a single three-step process because it was technically possible to do so.

This issue, at the intersection of design theory and project management, deserves further investigation. Project management research should analyze the relationship between product 
architecture and project management to understand better how they interact [see 29, 49, 63 for pioneering work on this question].

From the organizational point of view, the strategic management of a portfolio of trials too raises important challenges.

At the most general level, the existence of a powerful management structure in charge of the entire project is a condition sine qua non. Somebody must be able to supervise the entire project, i.e. define the different solutions, understand their relationships (and therefore their architecture), evaluate their progression, and make decisions according to the situation (stop, keep both, combine, redeploy resources, or add a new option). In our case this was the role of the project leaders, first and foremost Leslie Groves and Robert Oppenheimer, who were among the few to have a global view of the entire effort, understand the processes at work and, last but not least, benefit from full US government support.

But at a more micro level, the analysis of the Manhattan case reveals the difficulty of Mr. Skeptic's task ${ }^{3}$. Los Alamos turns out to be an extraordinary place to study the strategy of parallel approaches, since it was the final step of the entire endeavor. The laboratory received materials from the different sites, put them in the required form (both in metallurgy and geometry), designed and produced the bombs. The leaders constantly had to keep in mind the state of the different solutions. A letter from Oppenheimer to Groves shows the extent to which the task was organizationally demanding. At the height of the spontaneous fission crisis, Oppenheimer argued for not abandoning the plutonium gun completely despite the spontaneous fission problem. As he explained, the results on spontaneous fission "are new and since there is a possibility that the interpretation place on them may not be completely correct, it was agreed that although the discontinuance of the purification and neutron-less assembly program [part of the plutonium gun program] should be started immediately, it

\footnotetext{
${ }^{3}$ In their landmark 1958 paper, Klein and Meckling [43] opposed two ways of managing R\&D projects: Mr. Optimizer tries to find the optimal design at the outset whereas Mr. Skeptic recognizes that uncertainty is too high to do so. He thus makes "deliberate effort to keep his program flexible in the early stages of development so that he can take advantage of what he has learned. (...) In order to maintain flexibility he commit resources to development only by stages, reviewing the state of his knowledge at each stage prior to commitments "( $\mathrm{p}$ 357). They demonstrate the superiority of Mr. Skeptic's approach for R\&D projects.
} 
should be so conducted that at any time within the next month a return to these programs can be made without loss of more than a month's time. In particular, no essential personnel or installations should be permanently lost to the project within that period" (Oppenheimer to Groves, July 18, 1944; quoted in [6], p. 243).

Oppenheimer’s position exemplifies the organizational problems raised by the existence of "unk unks": it is never possible to be certain in advance that a solution is the good one. Thus, one must be ready to organize the transfer of people and knowledge from one trial to another. Resource fluidity [30] plays here a fundamental role. It gives managers the ability to move quickly among trials. The corollary and challenge of such an approach is the absence of a stable structure. Los Alamos, indeed, was an organization "whose structure was by nature ephemeral; experiments and responsibilities changed overnight as priorities that the war gave to the project changes” [6, p. 247]. As we have seen, the laboratory experienced a sequence of reorganizations during the War, moving from an academic-like institution to a huge scientific-industrial complex.

The normative uncertainty [16] that ruled Los Alamos was nonetheless balanced by a few rigid rules and focal points. Robert Oppenheimer was one of them. As Victor Weisskopf [17] recalled, "it was his continuous and intense presence, which produced a sense of direct participation in all of us; it created that unique atmosphere of enthusiasm and challenge that pervaded the place throughout its time”. The colloquium, a weekly plenary meeting, was another powerful means to help laboratory members understand the meaning of their work, and set the direction and pace of action. As explained by Thorpe and Shapin [16, p. 570-572), “The Colloquium, more than any other local organizational form, was understood both to express and to enable solidarity and integration. Los Alamos scientists were, almost without exception, highly concerned that each should have an overall sense of how their specialized work fitted into the specialized work being done by others, and into the instrumental goals of the laboratory as a whole. Information, they reckoned, should circulate throughout the laboratory as efficiently as practicable. (...) The solution was simply to provide for more face-to-face and free interaction, to encourage meetings and discussions at as many levels as possible and among as many specialized work groups as possible. This is how and why the weekly Colloquium for all staff members assumed such importance. The Colloquium was considered important as a means of disseminating 
information, and also as a way of creating solidarity and face-to-face accountability (...) General Groves agreed that the Colloquium 'existed not so much to provide information as to maintain morale and a feeling of common purpose and responsibility.". Los Alamos thus provides a most valuable large-scale case for the analysis of project management with unforeseeable uncertainties. It demonstrates that in such a situation nobody can determine ex ante how to organize the project. Managers must continuously adapt the organization to newly available knowledge, while not losing control of the project. The Manhattan project contributes to a growing body of work which underlines the need to balance structure and flexibility, to combine tight centralization and open debate in order to deal with and make sense of complex and uncertain managerial situations [24, 26, 49, 66]. This question, at the intersection between project management, innovation management and works on highreliability organizations, deserves further research.

\section{CONCLUSION : PROJECT MANAGEMENT AS STRATEGY MAKING}

The study of the Manhattan Project helps us advance our knowledge on parallel strategy in projects with unforeseeable uncertainty. Our analysis shows that the managerial interest of the parallel approach lies not only in the opportunity to pick the best solution once enough information is available, but also in the possibilities it opens for redeploying resources, combining trials, or adding new ones as the project moves forward. We have discussed the technical and organizational implications of this process. In so doing, we have tried to add to a growing body of research on the management of highly innovative projects, specifically the framework proposed by Loch et al. [49].

There was of course some specificity to the case under study. Given the wartime context, speed was of the essence. The Manhattan Project benefited from the full support of President Franklin D. Roosevelt and his administration, and this ensured almost unlimited resources, as well as the mobilization of the entire US industry (DuPont, Union Carbide, General Electric, Chrysler, Westinghouse, Tennessee Eastman and many others) and science (E. Fermi, J. Franck, E. Lawrence, A. Compton, J. Chadwick, E. Wigner, H. Urey were all Nobel Prize winners). Wartime circumstances, however, do not constitute a limitation of our findings. The availability of resources made it easier to implement a massive parallel approach. But it also gave Manhattan Project managers the freedom to 
use a wide variety of strategies, thus providing us with the opportunity to study the complexity of the process of managing parallel approaches. Moreover, both the problem of managing unforeseeable uncertainty, and multiple strategy as one of its solutions, are generic. Exploring the technical and organizational questions they raise deserve further research, particularly in order to analyze and formalize the conditions that allow the combination of options.

At a more general level, we have tried to contribute to a renewal of research on project management. The Manhattan Project foreshadows fundamental practices aimed at managing what is now called projects with unforeseeable uncertainty [49], projects with uncertain outcomes [53] or “exploration projects” [46]. In such a perspective, projects are a way of organizing the exploration of emerging innovation fields. But engaging in exploration entails a fundamental shift in project management methodology. As this research stream demonstrates, exploration situations do not allow for an ex-ante definition of the goal and the means to reach it. Projects themselves thus became highly uncertain and take on the features of reflexive probe-and-learn processes. They became a fundamental component of search processes [19]. Thus we cannot make the assumption that project strategy is given at the beginning. The dominant view of a project as the "obedient servant" of its parent organization is irrelevant here [21]. On the contrary, projects appear as a way to make strategy. They are a fundamental component of the emerging, bottom-up part of an organization's strategy process $[25,28]$. This observation requires broadening the traditional concepts of a project "mission” and a "specification" from given targets, to open problems for which the project proposes solutions. We hope that our historical detour through the Manhattan Project may help build such an alternative model of project management. 


\section{ACKNOWLEDGMENTS}

We are especially indebted to C. Loch and C. Baldwin for many useful suggestions on a previous version of this paper. We also thank the guest editor and three anonymous reviewers for their helpful comments, with a special mention for the insightful 12 page report of one of them. As usual, all remaining mistakes are my own.

\section{REFERENCES}

\section{On the Manhattan Project}

[1] Bird K, Sherwin M. 2005. American Prometheus. The Triumph and Tragedy of J. Robert Oppenheimer. Alfred A. Knopf: New-York

[2] Gosling F. 1999. The Manhattan Project. US Department of Energy (DOE/MA-0001 - 01/99)

[3] Groves L. 1962. Now It Can Be Told. The Story of the Manhattan Project. Da Capo Press: New-York

[4] Hawkins D. 1961. Manhattan District History. Project Y, the Los Alamos Project. Vol. I: Inception until August 1945. Los Alamos National Laboratory

[5] Hewlett R, Anderson O. 1962. The New World, 1939-1946. Volume I of a History of the United States Atomic Energy Commission. The Pennsylvania State University Press: University Park, PA

[6] Hoddeson L, Henriksen P, Meade R, Westfall C. 1993. Critical Assembly. A Technical History of Los Alamos during the Oppenheimer Years, 1943-1945. Cambridge University Press: NewYork

[7] Jones V. 1985. Manhattan: the Army and the Bomb. Center of Military History: Washington, D.C.

[8] Kelly C. 2007. The Manhattan Project. Black Dog \& Leventhal: New-York

[9] MacKenzie D, Spinardi G. 1995. Tacit Knowledge, Weapons Design, and the Uninvention of Nuclear Weapons. The American Journal of Sociology 101(1): pp. 44-99 
[10] Malloy S. 2008.Atomic Tragedy. Henry L. Stimson and the Decision to Use the Bomb Against Japan. Cornell University Press: New-York

[11] Norris R. 2002. Racing for the Bomb. General Leslie R. Groves, The Manhattan Project's Indispensable Man. Steerforth Press: South Royalton, Vermont

[12] Rhodes R. 1986. The Making of the Atomic Bomb. Simon \& Schuster: New-York

[13] Serber R. 1992. The Los Alamos Primer. The First Lectures on How to Build an Atomic Bomb. University of California Press: Berkeley

[14] Smyth H. 1945. Atomic Energy for Military Purposes. Princeton University Press. Reprinted in Reviews of Modern Physics, vol. 17 n4, pp. 351-471: Princeton

[15] Thayer H. 1996. Management of the Hanford Engineer Works in World War II. How the Corps, DuPont and the Metallurgical Laboratory fast tracked the original plutonium works. American Society of Civil Engineers Press: New-York

[16] Thorpe C, Shapin S. 2000. Who Was J. Robert Oppenheimer? Charisma and Complex Organization. Social Studies of Science 30(4): pp. 545-590

[17] Weisskopf V. 1967. A memorial to Oppenheimer. Physics Today 20(10)

\section{Other references}

[18] Abernathy W, Rosenbloom R. 1969. Parallel Strategies in Development Projects. Management Science 15(10): pp. B486-B505

[19] Adler P, Obstfeld M. 2007. The role of affect in creative projects and exploratory search. Industrial and Corporate Change 16(1): pp. 19-50

[20] Alchian A, Kessel R. 1954. A proper role of system analysis. D-2057. RAND corporation

[21] Artto K, Kujala J, Dietrich P, Martinsuo M. 2008. What is project strategy? International Journal of Project Management 26(1): pp. 4-12

[22] Arrow K. 1955. Economic Aspects of Military Research and Development. D-3142. RAND Corporation

[23] Baldwin C, Clark K. 2000. Design rules: the power of modularity. The MIT Press: Cambridge, MA 
[24] Bigley G, Roberts K. 2001. The Incident Command System: High-Reliability Organizing for Complex and Volatile Task Environments. Academy of Management Journal 44(6): pp. 12811299

[25] Brady T, Davies A. 2004. Building Project Capabilities: From Exploratory to Exploitative Learning. Organization Studies 25(9): pp. 1601-1621

[26] Brown SL, Eisenhardt KM. 1997. The art of continuous change: linking complexity theory and time-paced evolution in relentlessly shifting organizations. Administrative Science Quarterly 42(1): pp. 1-34

[27] Brown SL, Eisenhardt KM. 1998. Competing on the edge. Strategy as structured chaos. Harvard Business School Press: Boston, MA

[28] Burgelman R. 2003. Strategy is destiny. How strategy making shapes a company's future. The Free Press: New-York

[29] Danilovic M, Browning T. 2007. Managing complex product development projects with design structure matrices and domain mapping matrices. International Journal of Project Management 25: pp. 300-314

[30] Doz Y, Kosonen M. 2008. Fast Strategy. Wharton School Publishing: Harlow

[31] Eisenhardt KM. 1989. Building theories from case study research. Academy of Management Review 14(4): 532-550

[32] Emirbayer M, Mische A. 1998. What is Agency? American Journal of Sociology 103(4): pp. 963-1023

[33] Freeman C, Soete L. 1997. The Economics of Industrial Innovation (3rd ed.). The MIT Press: Cambridge, MA

[34] Glaser B, Strauss A. 1967. The discovery of grounded theory. Strategies for qualitative research. Aldine Publishing Company: Chicago

[35] Hargadon A. 2003. How Breakthroughs Happen. Harvard Business School Press: Boston, MA

[36] Hargadon A, Douglas Y. 2001. When Innovations Meet Institutions: Edison and the Design of the Electric Light. Administrative Science Quarterly 6(3): pp. 476-501 
[37] Henderson R, Clark K. 1990. Architectural innovation: the reconfiguration of existing product technologies and the failure of established firms. Administrative Science Quarterly 35(1): pp. 9-30

[38] Hitch C, McKean R. 1960. The Economics of Defense in the Nuclear Age. Harvard University Press: Cambridge, MA

[39] Hounshell D. 2000. The Medium is the Message, or How Context Matters: The RAND Corporation Builds an Economics of Innovation, 1946-1962. In A Hughes, T Hughes (Eds.), Systems, Experts and Computers. The Systems Approach in Management and Engineering in World War II and After: pp. 255-310. The MIT Press: Cambridge, MA

[40] Huchzermeier A, Loch C. 2001. Project Managemen Under Risk: Using the Real Options Approach to Evalluate Flexibility in R\&D. Management Science 47(1): pp. 85-101

[41] Hughes T. 1983. Networks of Power. Electrification in Western Society, 1880-1930. The John Hopkins University Press: Baltimore

[42] Kieser A. 1994. Why Organization Theory Needs Historical Analysis - And How This Should Be Performed. Organization Science 5(4): pp. 608-620

[43] Klein B, Meckling W. 1958. Application of Operations Research to Development Decisions. Operations Research 6(3): pp. 352-363

[44] Langley, A. 1999. Strategies for theorizing from process data. Academy of Management Review, 24: 691-710.

[45] Langlois R, Robertson P. 1992. Networks and innovation in a modular system: lessons from the microcomputer and stereo components industries. Research Policy 21: pp. 297-313

[46] Lenfle S. 2008a. Exploration and Project Management. International Journal of Project Management 26(5): pp. 469-478

[47] Lenfle S. 2008b. Proceeding in the dark. Innovation, project management and the making of the atomic bomb. CRG Working Paper(08-001)

[48] Lenfle S, Loch C. 2009. Lost Roots: How Project Management Came to Emphasize Control over Flexibility and Novelty. California Management Review, vol. 53, n¹, pp. 32-55. 
[49] Loch C, DeMeyer A, Pich M. 2006. Managing the Unknown. A New Approach to Managing High Uncertainty and Risks in Projects. John Wiley and Sons, Inc.: Hooboken, New Jersey

[50] Loch C, Terwiesch C, Thomke S. 2001. Parallel and Sequential Testing of Design Alternatives. Management Science 45(5): pp. 663-678

[51] Luehrman T. 1998. Strategy as a Portfolio of Real Options. Harvard Business Review(September-October): pp. 89-99

[52] McGrath R, McMillan I. 2000. The entrepreneurial mindset: strategies for continuously creating opportunity in an age of uncertainty. Harvard Business School Press: Boston, MA

[53] McGrath R, McMillan I. 2009. Discovery-Driven Growth. A Breakthrough Process to Reduce Risk and Seize Opportunity. Harvard Business School Press: Cambridge, MA

[54] Marples D. 1961. The decisions of engineering design. IEEE Transactions of Engineering Management 2 : pp. 55-71.

[55] Mohr L. 1982. Explaining Organizational Behavior. Josey-Bass Publishers: San Francisco

[56] Nelson R. 1959. The economics of parallel R and D efforts: a sequential-decision analysis. Rand Corporation Working Papers (RM-2482)

[57] Pich M, Loch C, DeMeyer A. 2002. On Uncertainty, Ambiguity and Complexity in Project Management. Management Science 48(8): pp. 1008-1023

[58] Sanchez R, Mahoney J. 1996. Modularity, flexibility and knowledge management in product and organization design. Strategic Management Journal 17: pp. 63-76

[59] Schwartz E, Trigeorgis L. 2004. Real Options and Investment under Uncertainty. Classical Readings and Recent Contributions. The MIT Press: Cambridge, MA

[60] Shenhar A, Dvir D. 2007. Reinventing Project Management. Harvard Business School Press: Boston, MA

[61] Siggelkow N. 2007. Persuasion with case studies. Academy of Management Journal 50(1): pp. 20-24

[62] Sommer S, Loch C. 2004. Selectionism and Learning in Projects with Complexity and Unforseeable Uncertainty. Management Science 50(10): pp. 1334-1347 
[63] Sosa M, Eppinger S, Rowles C. 2004. The Misalignment of Product Architecture and Organizational Structure in Complex Product Development. Management Science 50(12): pp. $1674-1689$

[64] Ulrich K. 1995. The role of product architecture in the manufacturing firm. Research Policy 24: pp. 419-440

[65] Van de Ven A, Polley D, Garud R, Venkataraman S. 1999. The innovation journey. Oxford University Press: New-York

[66] Weick K, Sutcliffe K. 2007. Managing the Unexpected. Resilient Performance in an Age of Uncertainty (2nd ed.). Jossey-Bass: San Francisco

[67] Wheelwright S, Clark K. 1992. Revolutionizing product development. Quantum leaps in speed, efficiency and quality. The Free Press: New-York

[68] Yin R. 2003. Case Study Research. Desing and Methods. (3rd ed.). Sage Publications: Thousand Oaks, CA 


\section{FIGURES}

\section{Figure 1. The principle of nuclear chain reaction}

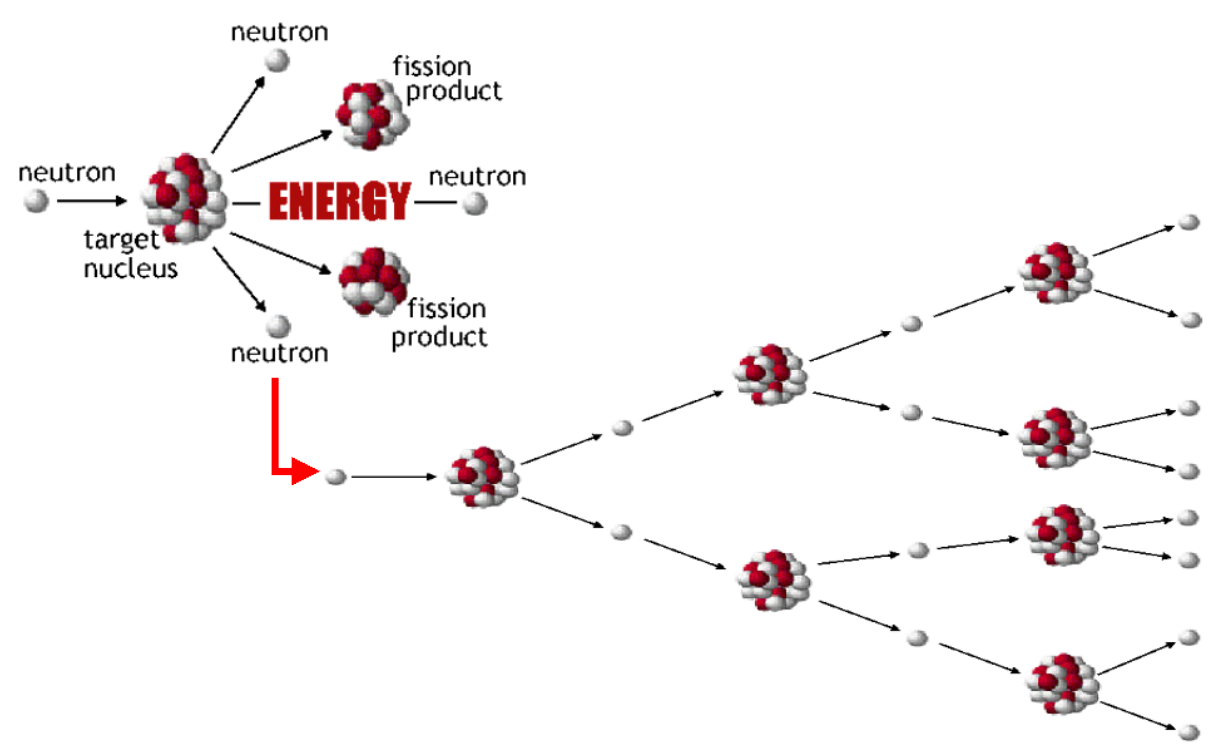

Source : http://www.cfo.doe.gov/me70/manhattan/resources.htm

Figure 2. Alternative bomb designs at the Berkeley seminar (July, 1942)

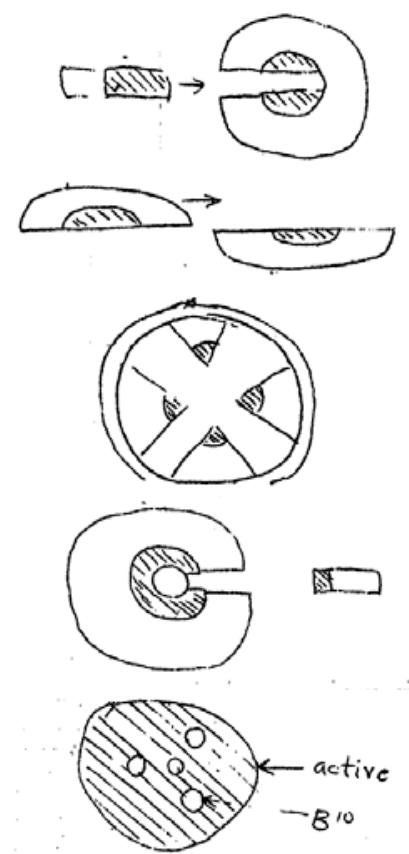

Source: Adapted from R. Serber, “The Los Alamos Primer,” Los Alamos National Laboratory Research Library, 1943. Approved for public release in 1996. Available online at http://www.cfo.doe.gov/me70/manhattan/publications/LANLSerberPrimer.pdf. 
Figure 3: organization of the project

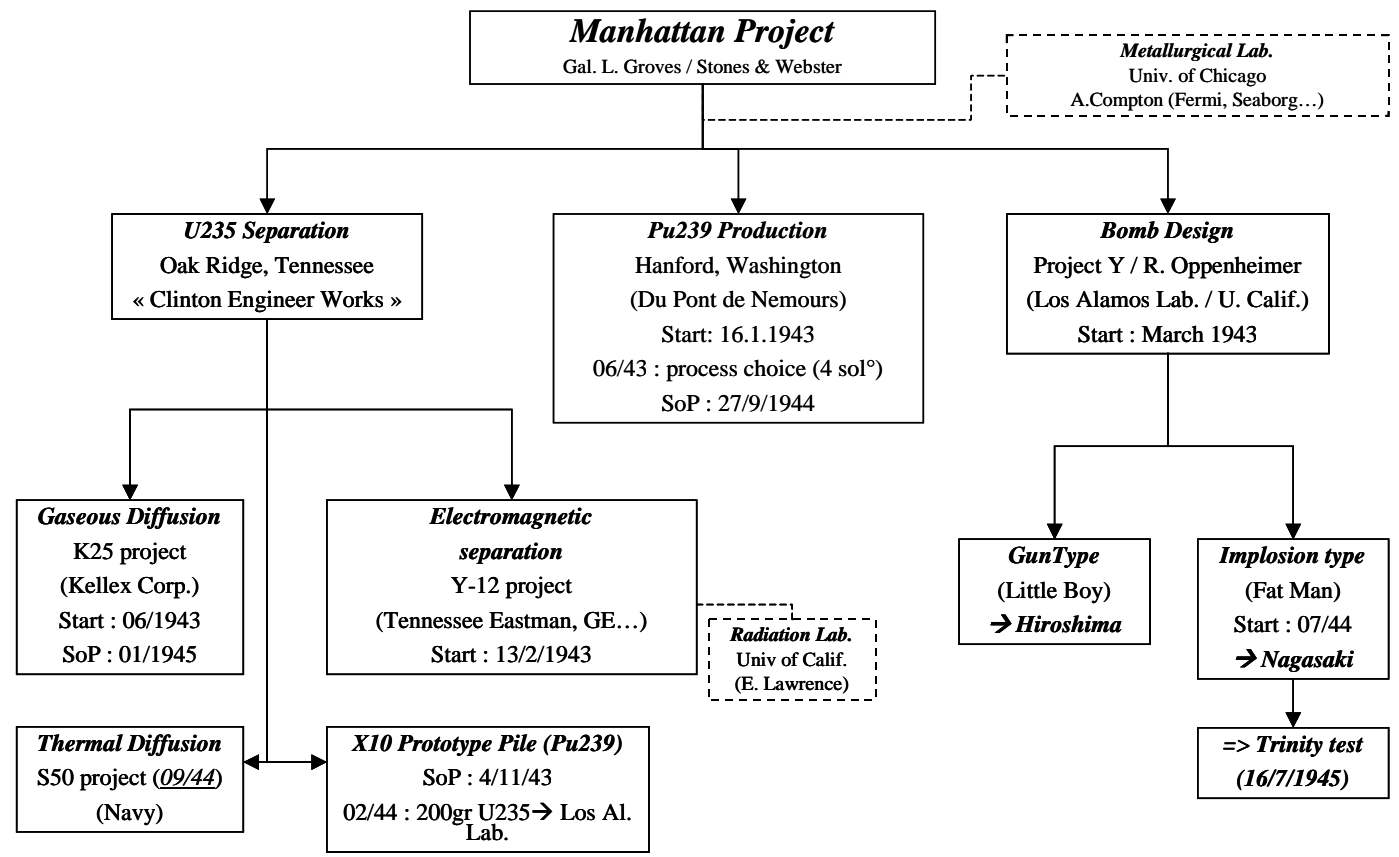

Note: This figure describes the "scientific" part of the Manhattan Project. We deliberately leave aside the other dimensions (uranium supply, espionage, B29 modifications, Tinian base construction in the Pacific and crew training) that are less important for the analysis of parallel strategy management. A complete description is available in [47].

Figure 4: planning of the Manhattan Project

\begin{tabular}{|c|c|c|c|c|c|c|c|c|c|c|c|c|c|c|c|}
\hline & \multicolumn{4}{|c|}{1942} & \multicolumn{4}{|c|}{1943} & \multicolumn{4}{|c|}{1944} & \multicolumn{3}{|c|}{1945} \\
\hline & $\mathrm{T} 1$ & $\mathrm{~T} 2$ & T3 & T4 & $\mathrm{T} 1$ & $\mathrm{~T} 2$ & T3 & $\mathrm{T} 4$ & T1 & T2 & T3 & $\mathrm{T} 4$ & $\mathrm{~T} 1$ & $\mathrm{~T} 2$ & T3 \\
\hline \multicolumn{16}{|c|}{ Research on Nuclear Physics (Met Lab \& co.) } \\
\hline \multirow{2}{*}{\multicolumn{16}{|c|}{ L. Groves - Project Director }} \\
\hline & & & & & & & & & & & & & & & \\
\hline \multicolumn{16}{|l|}{ Gazeous diffusion (Oak Ridge) } \\
\hline \multicolumn{16}{|c|}{ Electromagnetic separation (Oak Ridge) } \\
\hline \multirow{2}{*}{\multicolumn{16}{|c|}{ Thermal Diffusion (Oak Ridge) }} \\
\hline & & & & & & & & & & & & & & & \\
\hline \multicolumn{16}{|l|}{ x10 Prototype Pile (Oak Ridge) } \\
\hline \multicolumn{16}{|l|}{ Plutonium production (Hanford) } \\
\hline \multirow{2}{*}{\multicolumn{16}{|c|}{ Gun Type Bomb Design (Los Alamos) }} \\
\hline & & & & & & & & & & & & & & & 1 \\
\hline \multicolumn{16}{|c|}{ Implosion Type Bomb Design (Los Alamos) } \\
\hline \multicolumn{16}{|l|}{ Modification des B29 } \\
\hline \multicolumn{16}{|l|}{ 509th Composite group } \\
\hline & & & & & & & & & & & & & & & \\
\hline Construction base de Tinian & & & & & & & & & & & & & 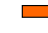 & & $\square$ \\
\hline
\end{tabular}

Source : [47] 
Figure 5. Gun type fission bomb (from [47])

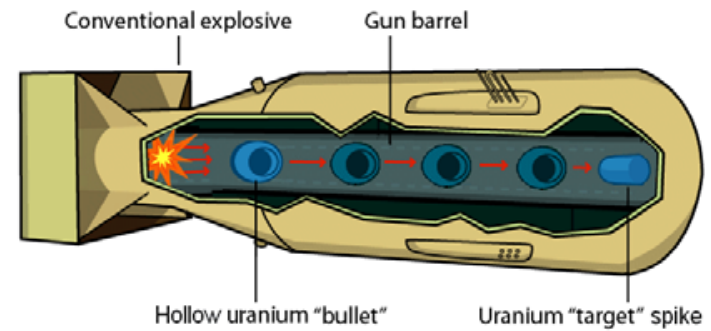

Figure 6. Implosion type fission bomb (from [47])

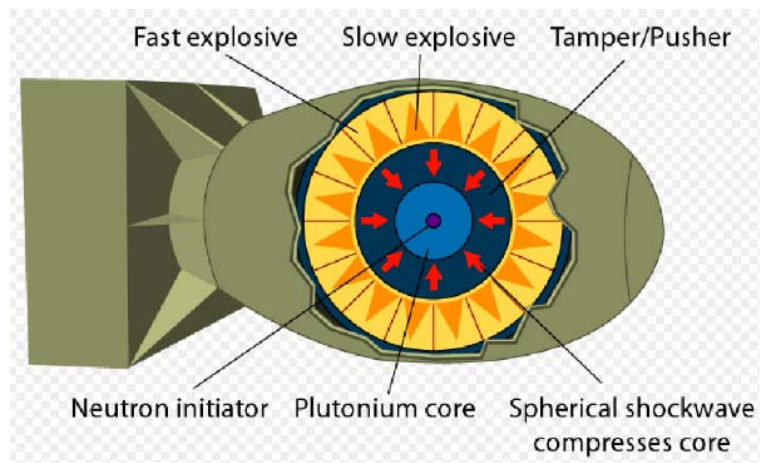

Figure 7. The evolution of the Manhattan Project

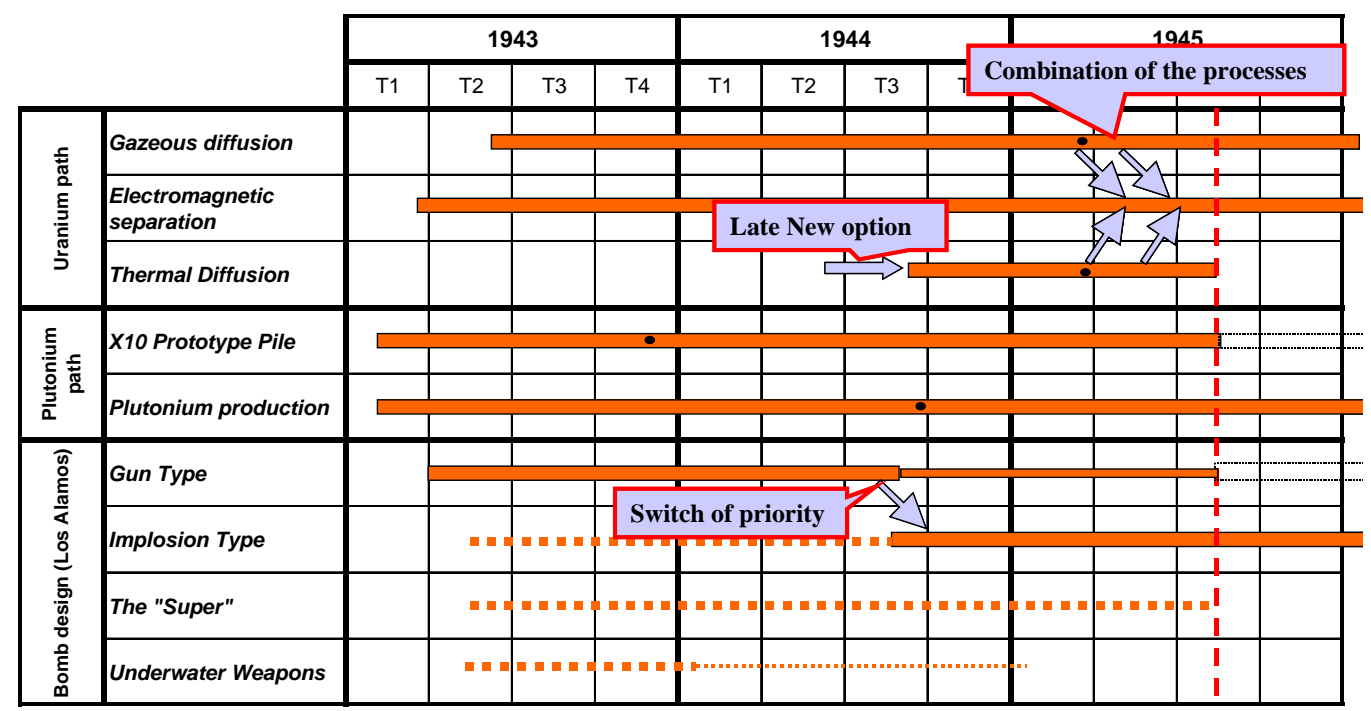

